\title{
Eozinofilni pustulozni folikulitis otroške dobe
}

\section{Eosinophilic Pustular Folliculitis of Infancy}

Klara Cvenkel, Mateja Starbek Zorko

\section{Izvleček}

Eozinofilni pustulozni folikulitis otroške dobe (EPFI) je redka, idiopatska, ponavljajoča se samoomejujoča kožna bolezen. Kaže se $s$ folikularno ležečimi papulami ali pustulami $z$ eozinofilno infiltracijo. Spremembe navadno najdemo v lasišču, lahko pa se pojavijo tudi drugje po glavi, vratu, trupu ali udih. Bolezen se največkrat pojavi v prvih mesecih življenja in poteka brez pridruženih sistemskih znakov. Navadno v nekaj mesecih do letih spontano izzveni. Zdravniki je pogosto ne prepoznajo in jo zato neustrezno (tj. prekomerno) zdravijo.

Ključne besede: eozinofilni pustulozni folikulitis otroške dobe, EPFI, dermatoza, pustule, otroci, eozinofilija.

\section{Abstract}

Eosinophilic pustular folliculitis of infancy (EPFI) is a rare, idiopathic, recurrent, self-limiting skin disease. It presents as papulopustules and folliculitis with eosinophilic infiltrates. The lesions are usually located on the scalp but also on other parts of the head, neck, trunk, or extremities. Most often it occurs in the first months of life and proceeds without signs of systemic illness. EPFI usually resolves spontaneously within a few months to years and is often unrecognised by physicians and consequently overtreated.

Key words: eosinophilic pustular folliculitis of infancy, EPFI, dermatosis, pustules, infants, eosinophilia. 


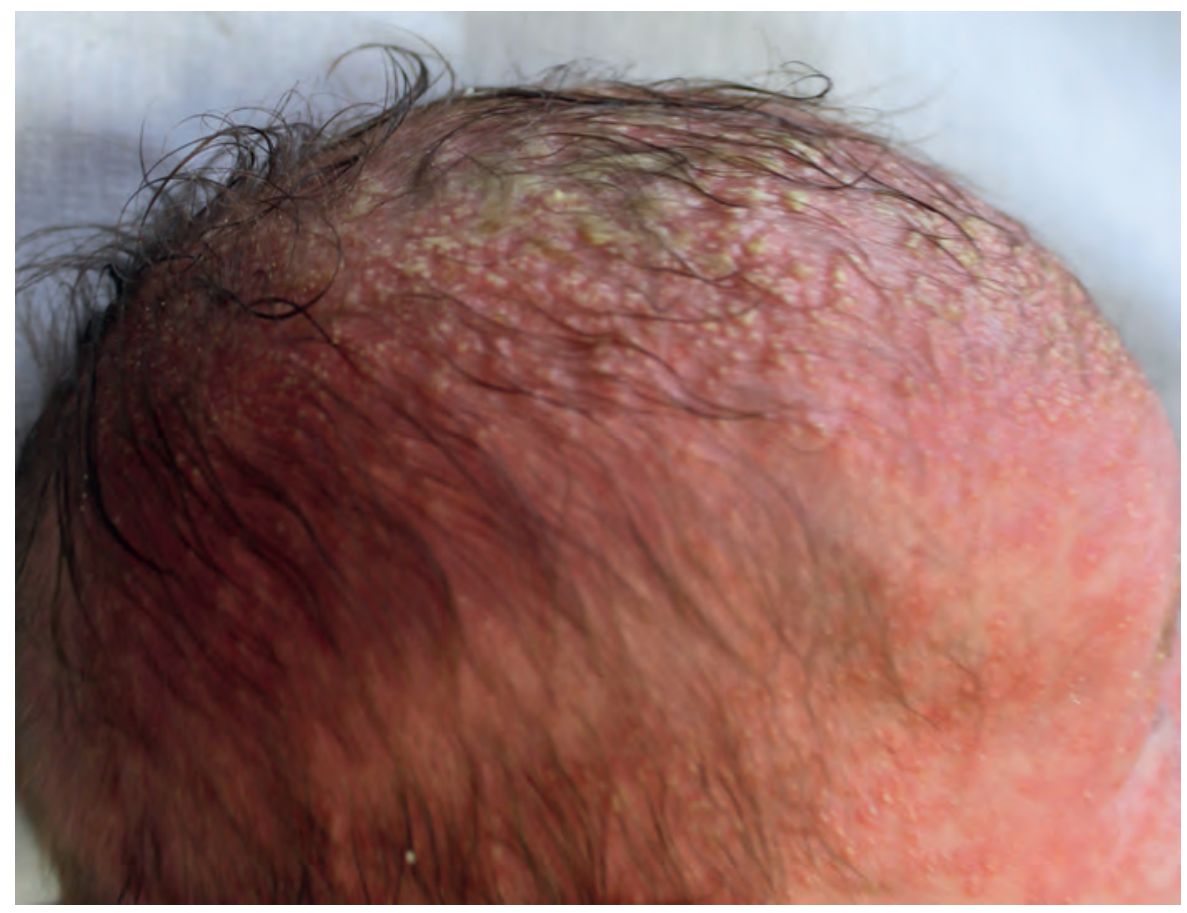

SLIKA 1. ZA EPFI ZNAČILNE PAPULOPUSTULOZNE KOŽNE SPREMEMBE NA LASIŠČU. FIGURE 1. TYPICAL SKIN MANIFESTATION OF EPFI (PAPULOPUSTULES ON THE PATIENT'S SCALP).

\section{Uvod}

Eozinofilni pustulozni folikulitis otroške dobe (angl. eosinophilic pustular folliculitis of infancy, EPFI) je Lucky leta 1984 (1) opisal kot posebno različico odrasle oblike bolezni, ki so jo prvič opisali leta 1970 (2). Klasični eozinofilni pustulozni folikulitis (EPF) se pojavlja predvsem pri odraslih Japoncih in se kaže s ponavljajočimi se anularnimi plaki s skupki sterilnih folikularno ležečih papul in pustul, ki prizadenejo obraz, trup in ude (3). Opisali so dva novejša tipa bolezni, in sicer EPF, povezan z imunosupresijo, ki je pogostejša različica (večina primerov pri bolnikih s HIV), in infantilni $\operatorname{EPF}(2,4)$.

EPFI je redka vnetna bolezen neznane etiologije, ki se najpogosteje pojavlja v prvih mesecih življenja. Pri $70 \%$ bolnikov se razvije pred 6 . mesecem starosti, le $5 \%$ bolnikov pa je ob postavitvi diagnoze starejših od 14 mesecev (5). Bolezen v $80 \%$ spontano izzveni do 3 . leta starosti, navadno pa traja od treh mesecev pa tudi več let (5). Dečki so štirikrat pogosteje prizadeti kot deklice $(5,6)$.
Patogeneza EPFI ni jasna, a obstajajo različne teorije. Omenjajo imunološke, hormonske in genetske vzroke ter preobčutljivostne reakcije (8-10). Zelo verjeten je imunološki vzrok, saj EPFI pogosto ugotavljamo pri nedonošenčkih, ki nimajo ustrezno razvitega imunskega sistema, $v$ anamnezi pa sistemsko okužbo s kandido $(6,7)$. To teorijo podpira tudi dejstvo, da se EPF pojavlja pri odraslih bolnikih z imunsko pomanjkljivostjo zaradi okužbe s HIV ali maligne bolezni, kot je T-celični limfom (8). Prav tako obstaja domneva, da bakterijske, virusne, glivične in parazitske okužbe lahko sprožijo eozinofilijo preko aktivacije Th2-celic ter kasnejše sproščanje citokinov interlevkina 4 in interlevkina 5. Klinične lastnosti okužb in EPFI se navadno zelo razlikujejo pa tudi v literaturi ni primerov osamitve povzročitelja okužbe pri bolnikih z $\operatorname{EPFI}(9,10)$.

Nekateri avtorji menijo, da EPFI ni specifična bolezen, ampak skupina bolezni, pri katerih je prisotna tkivna eozinofilija (toksični eritem novorojenčkov, pemfigoid, piki členonožcev, atopijski dermatitis, hipereozinofilni sindrom, reakcije na zdravila), ki se večinoma klinično kažejo povsem drugače kot EPFI (4).

\section{Klinična slika}

Ob izbruhu EPFI se pojavijo sterilne papule in pustule na eritematozni podlagi. Spremembe vedno najdemo v lasišču, v 65 \% lahko tudi na drugih delih telesa, npr. na obrazu, vratu, trupu in udih. Spremembe tvorijo skupki papul in pustul, prisotna je tudi srbečica. Sistemskih simptomov pri EPFI praviloma ni. Za razliko od EPF pri odraslih papule in pustule pri otrocih ne ležijo na tipičnih anularnih plakih (11, 12). Izbruhi svežih pustul se pojavljajo v intervalih na 1-12 tednov in v 1-4 tednih spontano izzvenijo. Celjenje poteka brez brazgotinjenja, lahko pa ostanejo povnetne hiperpigmentirane makule. Bolezen pri večini otrok do 3. leta starosti spontano izzveni, vendar opisujejo tudi primere, ko je bolezen trajala od 3 mesecev do 5 let (13).

\section{Diagnosticiranje}

Diagnoza EPFI temelji na tipični klinični sliki, poteku bolezni in dokazu eozinofilcev iz brisa pustul. Tkivna eozinofilija je vedno prisotna in jo lahko dokažemo s citologijo ali biopsijo kože, ki pokaže goste eozinofilne infiltrate. Pri vseh bolnikih ne najdemo pravega folikulitisa. Eozinofilci so lahko razširjeni v dermisu perifolikularno, interfolikularno ali periadneksalno (14).

Čeprav srbenje in krvno eozinofilijo ugotavljamo pri veliki večini bolnikov, se moramo zavedati, da je eozinofilija lahko prisotna le v akutni fazi izbruha. To pojasnjuje, zakaj je včasih pri nekaterih otrocih ne zaznamo. Mikrobiološki brisi pustul so negativni na bakterije, glive in viruse, čeprav se lahko pojavi sekundarna okužba z bakterijo Staphylococcus aureus (7). 


\section{Diferencialna diagnoza}

$\checkmark$ izogib nepotrebnim diagnostičnim postopkom in neprimernemu zdravljenju je nujno, da EPFI prepoznamo in bolezen razlikujemo od drugih bolezni s pustulami. Ob dvomu so nam pri postavitvi diagnoze $v$ pomoč starost bolnika ob pojavu bolezni, klinična slika, potek bolezni in mikrobiološke in / ali histološke ugotovitve.

$\checkmark$ diferencialni diagnozi vedno upoštevamo primarne nalezljive vzroke papulopustuloznih sprememb pri novorojenčkih in dojenčkih, kot so bakterijske (impetigo, listerioza, folikulitis), virusne (herpes simpleks, norice), glivične (folikulitis zaradi okužbe z glivo C. albicans ali glivo Malassezia sp.) in parazitne okužbe (pri mlajših bolnikih z garjami), ki jih moramo izključiti z ustreznimi mikrobiološkimi preiskavami $(3,5,6)$.

Tkivna eozinofilija s krvno eozinofilijo ali brez nje je značilna pri različnih kožnih boleznih, kot so toksični eritem novorojenčkov (lat. erythema toxicum neonatorum, ETN), reakcije po pikih, atopijski dermatitis, reakcije na zdravila in bulozne dermatoze. Zlasti zahtevno je razlikovanje med EPFI, ETN, infantilno akropustulozo (IA) in hiper -IgE sindromom (HIES). Tako EPFI kot IA se ponavljata, a so pri IA spremembe v večini prisotne na rokah in nogah. Pri IA v pustulah prevladujejo nevtrofilci in ne eozinofilci, ki jih v brisu najdemo pri EPFI. ETN se navadno prične v prvih tednih starosti in se ne ponavlja.

HIES je ob prvem pojavu težko razlikovati od EPFI, saj obe bolezni spremlja papulopustulozni dermatitis. Spremembe pogosto vidimo na obrazu in $v$ lasišču, kjer se poleg papul in pustul pojavljajo kraste kot posledica okužbe z bakterijo S. aureus. Za obe bolezni je značilna eozinofilija v krvi, zato ne preseneča, da so prvotno veliko bolnikov s HIES diagnosticirali kot EPFI (15). Za bolnike s HIES je značilno večje tveganje hudih okužb in skeletnih nepravilnosti, zato moramo otroke s HIES redno spremljati (5).
Ker gre pri EPFI za kronično kožno bolezen, ki jo navadno diagnosticiramo na osnovi klinične slike in pozitivnega brisa pustule na eozinofilce, otroka spremljamo, dokler bolezen spontano ne izzveni, ob dolgotrajnem poteku bolezni ali nejasnosti glede diagnoze (pridružene okužbe, razširjena oblika bolezni itd.) pa razmislimo o diferencialnodiagnostičnih možnostih in jih z dodatnimi preiskavami izključimo.

\section{Zdravljenje}

EPFI je samoomejujoča bolezen, zato jo pogosto neustrezno diagnosticiramo in po nepotrebnem zdravimo. Zdravljenje je simptomatsko. Aktivni izbruhi, ki so navadno kratkotrajni in se pojavljajo v neenakomernih intervalih, se dobro odzivajo na lokalne kortikosteroidne pripravke, lahko pa minejo tudi spontano. Posamezni opisi izboljšanja akutnega izbruha bolezni ob zdravljenju z lokalnimi antibiotiki ali celo sistemskimi antibiotiki so presenetljivi in so verjetno posledica naključja, saj bolezen mine spontano. Po drugi strani pa nekateri avtorji izboljšanje ob antibiotičnem zdravljenju pojasnjujejo $z$ antikemotaktično učinkovitostjo predpisanih antibiotikov, npr. eritromicina (16). $\checkmark$ splošnem bolnike ob zagonu EPFI zdravimo z lokalnimi kortikosteroidnimi pripravki, zdravljenje $z$ antibiotiki pa prihranimo za bolnike z morebitno sekundarno okužbo sprememb (17).

\section{Zaključek}

Eozinofilni pustulozni folikulitis otroške dobe (EPFI) je redka, a pogosto neprepoznana bolezen. Nanjo pomislimo pri dojenčku s papulopustuloznimi spremembami v lasišču, zlasti če se ponavljajo in jih spremlja krvna eozinofilija. Za zdravnike, ki se srečujejo s tovrstnimi bolniki, je pomembno, da bolezen poznajo in jo ustrezno prepoznajo, saj s tem pomirijo zaskrbljene starše in se predvsem izognejo nepotrebnima dodatnemu diagnosticiranju in zdravljenju.
Literatura

1. Lucky AW, Esterly NB, Heskel N, Krafchik BR, Solomon LM.Eosinophilic pustular folliculitis in infancy. Pediatr Dermatol 1984; 1: 202-6.

2. Nervi SJ, Schwartz RA, Dmochowski M. Eosinophilic pustularfolliculitis: a 40 year retrospect. Am Acad Dermatol 2006; 55: 285-9.

3. Buckley DA, Munn SE, Higgins EM. Neonatal eosinophilicpustular folliculitis. Clin Exp Dermatol 2001; 26: 251-5.

4. Ziemer M, Boer A. Eosinophilic pustular folliculitis in infancy:not a distinctive inflammatory disease of the skin. Am JDermatopathol 2005; 27: 443-55.

5. Hernández-Martín A, Nuño-González A, Colmenero I, Torrelo A. Eosinophilic pustular folliculitis of infancy: a series of 15 cases and review of the literature. J Am Acad Dermatol 2012; 68: 1: 150-5

6. Porriño-Bustamante ML, Sánchez-López J, Aneiros-Fernández J, Burkhardt P, Naranjo-Sintes R. Recurrent pustules on an infant's scalp with neonatal onset. Int J Dermatol 2016; 55: 505-8.

7. Finelt $\mathrm{N}$, Kristal L. Patient characteristics of neonatal eosinophilic pustulosis. Pediatr Dermatol 2013; 30: e204-7.

8. Fuhiyama T, Tokura Y. Clinical and histopathological differential diagnosis of eosinophilic pustular folliculitis. J Dermatol 2013; 40: 419-23.

9. Simon D, Simon HU. Eosinophilic disorders. J Allergy ClinImmunol 2007; 119: 1291-300;quiz 301-2.

10. Amerio $P$, Verdolini $R$, Proietto $G$, Feliciani C, Toto P, Shivji G, et al. Role of Th2 cytokines, RANTES and eotaxin in AIDS-associated eosinophilic folliculitis. Acta Derm Venereol 2001; 81: 92-5

11. Torrelo A, Mediero IG, Rabano A, Zambrano A. Pustulosiseosinofilica infantil: presentacion de tres casos. Actas Dermo-sifiliogr 1996; 87:697-700.

12. Giard F, Marcoux D, McCuaig C, Powell J, Russo P. Eosinophilicpustular folliculitis (Ofuji disease) in childhood: a review offour cases. Pediatr Dermatol 1991; 8:189-93.

13. Alonso-Castro L, Perez-Garcia B, GonzalezGarcia C, Jaen-Olasolo P. Eosinophilic pustular folliculitis in infancy: report of a new case. Dermatology online journal 2012; 18(10).

14. Taieb A. Infantile eosinophilic pustular "folliculitis" in infancy:a nonfollicular disease. Pediatr Dermatol 1994; 11: 186.

15. Van Dijk EM, de Vries E. Immunodeficiency: children with elevated IgE.Ned Tijdschr Allergie \& Astma 2013; 13: 108-13.

16. Duarte AM, Kramer J, Yusk JW, Paller A Schachner LA.Eosinophilic pustular folliculitis in infancy and childhood. AmJ Dis Child 1993; 147: 197-200

17. Isbouts LN, Weber EH, Marleen Veenstra, Mathijs Binkhorst Eosinophilic Pustular Folliculitis of Infancy, Case Report Published 2017, Article 1483 
Klara Cvenkel, dr. med.

Interna klinika

Univerzitetni klinični center Ljubljana

Mateja Starbek Zorko, dr. med.

(kontaktna oseba / contact person)

Otroški oddelek

Dermatovenerološka klinika

Univerzitetni klinični center Ljubljana in

Katedra za dermatovenerologijo

Medicinska fakulteta, Univerza v Ljubljani

prispelo / received: 14. 12. 2020

sprejeto / accepted: 7. 2. 2021

Cvenkel K, Starbek Zorko M. Eozinofilni pustulozni folikulitis otroške dobe. Slov Pediatr

2021; 28(2): 94-97. https://doi.org/10.38031/ slovpediatr-2021-2-04. 